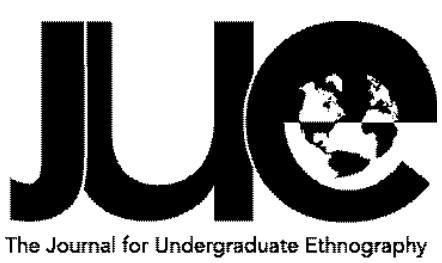

Volume 4 | Issue 1

\title{
Negotiating Development:An Ethnographic Study of Implemented and Latent Cultural Capital of the Christian Karen of Northern Thailand
}

\section{Malcolm McDermond}

Messiah College, mmcdermond14@gmail.com

\section{ABSTRACT}

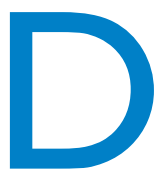

rawing upon my five months living with a Karen ethnic-minority family in Northern Thailand between February and July of 2013, I explore the ways in which development is negotiated and can be negotiated by utilizing cultural capital and other resources within the village of Melaoop. In order to do this I engage the broader body of development discourse and paradigms. Using data collected through my ethnographic research, I first present the cultural capital and the implemented techniques through which the Christian Karen of Melaoop negotiate development: primarily selling cultural products to outsiders, protecting the natural resources, and working with outsider non-government organizations. I also highlight my observations about the unique Christian Karen expressions of institutions of communality, gender, and religion that have a latent capacity to impact how development is negotiated in the future. Throughout this paper there is a palpable tension between the insider/outsider perspective seen not only in the locus of development but also in the collection of ethnographic research itself. My research illustrations how various opinions and actions indicate the primacy of religion, cultural ethics and beliefs, gender roles, and economic incentives as culturally formed institutions that impact how development pressures are negotiated both individually and communally.

Keywords: development, cultural capital, negotiation techniques, insider/ outsider perspectives 


\section{INTRODUCTION}

It was a hot afternoon in the long days before the monsoon rains came. We, Uncle Wit and I, were sitting on his porch lounging in the heat of the day. Warm winds stirred the trees in front of us. Something was stirring in his mind as well, I could see it on his face. He took a long drag from his banana leaf cigar. As he exhaled he said, "All this development is destroying the forest. People come here and cut down the trees and fish in our rivers. What can people give their children if not good nature? What kind of development is this that destroys the forest?" His words lingered in my mind long after the smoke he exhaled had drifted away in the warm breeze.

Development, as both ideology and practice, has garnered greater attention and debate in academic, economic and political circles than ever before. Universities the world over are offering degrees in sustainable development, international development, and public policy and development just to name a few. The development debate, however, has raged on for centuries since the first Europeans expanded their colonial empires, justifying this encroachment with rhetoric of progress, enlightenment and development. Over time the old paradigms and practices of empire have given way to many new forms and ideologies of development. The United Nations, arguably the most international and global association in the history of humankind, recognizes the need for local involvement and local initiative as the preferred means of development rather than a national or international level enterprise (Sachs 2011, 80). Even the International Monetary Fund and World Bank, two of the key actors in creating development paradigms, are reevaluating their own macro level stances on development (Güven 2012, 870). Despite these acknowledgements, the reigning paradigm for development is still one in which outsiders develop communities or areas in ways and means decided by non-local entities, as self-evidenced by the fact that these multinational organizations are dominating the creation of development paradigms.

If this is the kind of rhetoric of macro-level development, how then is development understood on the local level in local communities by local people? Are there cultural resources that local communities have been using to negotiate their own development and make known their own agenda in light of external forces? Are their cultural resources that local people are not utilizing that could be used in development projects and if so, do outsiders have any authority to speak into these communities about such resources? Is external initiated development always imperialistic and against the will of the people? These are just a few questions raised when we consider the complexities and nuances of the current state of development.

These questions were first raised in my mind during and after my ethnographic study of a Karen family in Northern Thailand. I saw earthmovers and cement trucks rumble along little dirt roads through the remote mountains as they laid cement and built new roads. I watched government bureaucratic buildings erected on land seized from tribal peoples. I saw rice fields destroyed to build bridges and bring police security. I listened as my host family enthusiastically talked about the exciting new development and empathized as they worried and pondered about the implications of such development for their lives and their children's lives.

Considering these experiences and questions, I determined to understand better the complexities of how local people negotiate development in light of their cultural resources and capital. This desire was born out of my own personal relationship with Karen people and my convictions and beliefs about the necessity of development for the world's underprivileged. The project and findings that follow are the products of these personal experiences, convictions and friendships that are so meaningful to me and those who shared them with me. I believe, however, that the relevance of this goes far beyond my own personal experience and can in many ways speak into the ongoing discussion about development. More and more we need to hear the voices of those who are directly impacted by the development policies and agendas of governments, transnational organizations and NGOs. 


\section{LITERATURE REVIEW}

To understand the contours of my research, I must first make clear the paradigmatic understanding of development with which I am dialoguing. One of the first and foremost agents in defining development is the United Nations. The comprehensive Millennium Development Goals were released by the UN in 2000 and have since become an authoritative basis for thinking about development. The Millennium Goals are comprised of eight broad objectives: 1) eradicating extreme poverty and hunger, 2) achieving universal primary education, 3) promoting gender equality and empowering women, 4) reducing child mortality, 5) improving maternal health, 6) combating HIV/ AIDS, malaria and other diseases, 7) ensuring environmental sustainability and 8) developing global partnership for development (United Nations Development Programme, 2012). These goals are focused on holistic development, recognizing the multifaceted reality of development.

However, these are merely goals and the precise processes of development are still highly contested. One of the most helpful models of development process that I relied upon was one in which development is oriented towards the needs of the community, endogenous, or originating within the community, selfreliant and ecologically sound (Ekins 1992, 99). Furthermore, it recognizes the agency of multiple stakeholders like the government, private sector and civil society in building and enriching development programs (Sachs 2011, 80). This particular model seeks to be as realistic, sustainable, holistic and local as possible.

More and more the consensus in development discourse is in favor of local or endogenous initiatives. Locally originating processes are quintessential to development. Chaikeu's study of hunger in rural communities indicated that indigenous social systems were better at recognizing and communicating hunger issues than external monitoring systems $(2009,47)$. What this study theorized and proved is that local people are active agents of change (Chaikeu et al. 2009, 44). Recognizing the importance of local agency is key to understanding the perspective with which I approach my own research.

The refocus from global or external actors to local actors also highlights other themes often missed in development discourse on the macro scale. Development, on the local scale, is primarily an external force that pervades the homes and dominates the discourse of those who the development initiatives are aimed at aiding (DeTemple 2008, 116). Considering this, it is not then in the ivory towers of academia, on the senate floors of international organizations or in the offices of international non-government organizations but the everyday homes of those impacted by development where development is most earnestly being negotiated.

Furthermore, development programs do at times generate conflicts of interest. Paladino's study of governmental carbon emissions regulation policy illuminates how such policies created real conflicts of needs between forest dwellers and government agencies $(2011,119)$. In this instance, traditional means of production were prohibited because of external governmental regulations based on macro level development goals. Those affected were not the policy makers per say but rather the local community.

Additionally, it is only on the local level that one can see the way in which development impacts and shapes ethnicity and vice-versa. In West Bengal, for example, ethnic minorities took forest management into their own hands as they contested the government forestry conservation practices and effectively negotiated the external Bengali government agendas in their own favor (Sivaramakrishnan 2000, 434). In India, however, new agricultural technologies effectively eroded traditional practices and culture (Samaddar 2006, 117). It appears then that the relationship between development and ethnicity is not always negative nor is it one sided, despite the prevalence of hegemony and ethnocentrism that has pervaded development rhetoric in the past.

So then, the development which I am in dialogue with throughout my research is a dialectic of many predominant development paradigms. Development as I refer to it in the following research is comprised of local, national and international aspects. It is a holistic concept aimed at the empowerment of individuals and communities. It is a powerful force that is changing both the natural and social landscapes it encounters, for better or ill. But most importantly, it is fluid and constantly negotiated by those it impacts.

This definition of development recognizes the importance of local and indigenous agency in development discourse and negotiation. It is for no small reason that the role of those impacted by development is considered so significant in this current discussion. Indigenous communities and ethnic minorities 
are those predominantly affected by development and the most vulnerable to the pressures of modernity that comes on its heels. New technologies that threaten traditional practices (Samaddar 2006, 117), government policy that divests people of traditional subsistence strategies (Hamayi 1997, 558, Kabuye 1999, 265) and creeping modernization that erodes unique religious and cultural worldviews (Torri et al. 2011, 184) are all examples of the negative impacts of development.

The erosion of culture and tradition should cause concern. Each unique cultural and ethnic group sees and creates meaning in the world through unique lenses (Nazarea 1999, 92). The loss of these unique perspectives could mean the loss of a particular worldview that has much to contribute to the global community. From an extrinsic perspective, indigenous knowledge is a resource to Western science and medicine (Stephenson 1999, 230). Traditional knowledge also encompasses agricultural and land management practices that maintain ecological fertility and health better than modern practices (Torri et al. 2011, 169). Not only can this knowledge be used to supplement Western scientific knowledge or environmental sustainability, it also is a key component of human cultural diversity, thereby enhancing humanity's overall cultural "fitness" (Hunn 1999, 27). If the cultures that hold this knowledge disappear, so do the practical benefits they have for the greater human community. But on an intrinsic level, these traditional cultures and their cumulative knowledge should be protected and conserved for their own sake.

As the above discussion highlights, development is a multifaceted and complex topic. Considering this, I intentionally drew upon multiple theoretical backgrounds to get a fuller understanding of this complex issue's breadth and scope. Most indigenous and traditional groups undergoing development are still rural, agrarian and in large part dependent upon their biological and material surroundings for subsistence. With this in mind, cultural materialism, as purported by Marvin Harris, is exceedingly relevant to understanding the cultural background of those impacted by development. Cultural materialism highlights the principle of infrastructural determinism, which means "the etic behavioral modes of production and reproduction probabilistically determine etic behavioral domestic and political economy which probabilistically determines behavioral and mental emic superstructure" (Harris 1979, 55-56). In other words, cultural materialism prioritizes infrastructure over su- perstructure because infrastructure is seen as the most basic interaction between culture and the natural world. This is all based upon the fact that biological restraints of nature are the greatest and thus most influential on human cultural infrastructure (Harris 1979, 57).

Cultural materialism's emphasis upon biological factors is highly relevant to the particular traditional context where I did my research. I take for granted the fact that "local cultural practices developed through the long interaction of ecology, cultural ideas and indigenous technology" (Samaddar 2006, 108). Therefore, any attempt at understanding cultural practices must also consider the ecological and material factors with which the particular culture interacts.

However, cultural materialism does not recognize the importance of superstructure in defining culture. Cultural materialism is a strand of theory that neglects or discounts the importance of symbolic superstructure in socio-cultural analysis (Knauft 1985, 333). Therefore, I drew upon the works of Peter Berger as a means of reconciling Harris' lack of consideration for the role symbolic factors and superstructure play in shaping culture. Of particular relevance is Berger's three step process of externalization, objectivation and internalization. Externalization is the process by which the subjective human creates the external social world. Objectivation is the process by which this external social world assumes an objective reality of its own independent of the human actor. Finally, internalization is the completion of the cycle as the now objective social world reflects back upon and impacts the human agent from which it originated (1967, 4). Why though is this process significant? In any context, how one defines the social reality one is confronted with determines the essence of that reality. As development enters into rural community and community members need to negotiate this development, the processes of externalization, objectivation and internalization will define how development occurs within the community.

One final theory relevant to the research considers the actual ability of those impacted by development to negotiate the forces of development. With this in mind, social capital must be brought into the discussion. Social capital is "a particular kind of resource" available to actors because of "changes in relations" between people (Coleman 1988, 267). Social capital can take the form of obligations and expectations, channels of informa- 
tion and social norms and sanctions (Coleman 1988, 269-271). Each of these provides resources to those who can "cash in" on their social relationships to better exert their own influence on the external world. This is particularly relevant to this research because what social capital exists, what is implemented and what is latent within these communities are all questions of particular interest to me. Furthermore, in light of the previously mentioned importance of local actors and agency in development, the need for positive social capital is paramount.

Despite the antithetical nature of the two theories, cultural materialism and the social construction of reality: both theories provide necessary perspectives to my research. Cultural materialism highlights the reality that culture is built upon the specific environmental context in which that said culture arises. This is particularly true of agrarian and rural communities highly dependent upon the land to meet their basic needs. However, cultural norms, myths and taboos do reflect back upon the environment in which the culture is situated and the culture itself. To strike a compromise between Harris and Berger, I must then consider both the particular environmental context or infrastructure as well as the relevant socio-cultural environment or objective social structure.

In short, no one single theory could fully encompass the diversity and complexity of development issues. Therefore, the constructive tension that arises from each of these three theories provides a breadth that covers both the material and social factors of development relevant to my subsequent research.

\section{FIELD SITE DESCRIPTION}

I did my ethnographic research in the rural Thai village of Melaoop, (Me-la-oop), in Chiang Mai province, roughly 5 hours outside of the largest northern Thai city, Chiang Mai. Melaoop is located in the greater area of the Musekii plateau, a unique geographic and ethnic region in the province. Musekii is of higher elevation than most of the surrounding province. It is known for its abundant tropic dry forests which are composed of large portions of conifers, a unique biological characteristic. The majority of land in the region is still covered by the distinctive forest. Geographically, Musekii is a land of seemingly endless hills and vast gullies. Most of the population and village development is located within these valleys rather than the hill tops. Melaoop is situated between two chains of hills within the Musekii plateau in a gently sloping and picturesque river valley. The village itself 
is located on the side of the southern hills overlooking the rice paddies in the low lying river valley.

Melaoop village contains roughly seventy households, a wat (Buddhist temple), a church, three small in-house convenience stores, a mechanic, a primary school and hostel for children attending the school, and a small rural health center just outside the village up the main road. Electricity and running water are both available but sporadic periods of unavailability persist. There would be days when I would enjoy the slower process of making tea over an open fire. The main street is, at the time of my research, partially paved near the school and up the hillside. However, much of the village is unpaved dirt road. This is subject to change as recent Thai governmental construction programs and the establishment of a new district government seat are currently building roads and expanding infrastructure in the Musekii area. The road has, in many ways, become a symbol of external development with ambiguous meaning for the people most directly impacted.

Families meet basic needs by using mixed economic subsistence. The major means of subsistence is wet-rice cultivation in the adjacent rice paddies. Rice from these paddies is the main staple of the local diet. A large portion of my time with my host family was spent in the rice fields either preparing for the planting season or planting itself. Secondary to agriculture is wage earning jobs in connection with the major institutions of the school and hostel, the local health center, the church and an ecolodge tourist venture in an adjacent village. Most wages go towards luxury foods such as meats, candies, teas and spices, children's education or home improvement. There is also widespread horticulture and hunting and gathering which make up smaller but equal parts of the average villagers diet. Pig husbandry is also common but mostly used for wedding dowries or special ritual occasions. Socio-economically, all but the trained health professionals at the rural clinic can be consider part of a peasant class.

Home construction needs are also meet in a variety of ways. Most homes are cinderblock, cement, hardwood, bamboo or recycled woods and materials. Cinderblock and cement are purchased at supply stores in a village about a thirty minute drive away. Hardwood, of greater quality, is purchased in the nearest city, Pai, which is an hour and fifteen minutes drive away. Some woods are harvested locally in the forest along with bamboo. Additionally, most families have recyclable construction materials from previous building projects which are stored and used as needed. Roofing and flooring also vary greatly between households. Some households are primarily bamboo or wooden flooring. The wealthier homes have tiling or cement floors. Roofing is almost unanimously tin sheet, due to its widespread availability and ease of use.

Ethnically, Melaoop is a Karen village. Karen are one of the largest ethnic groups in Thailand and are generally grouped into the "hilltribes" with other ethnically diverse groups by Thai people. However, there is much diversity amongst the Karen of Thailand. The particular Karen living in the Musekii area are part of the subgroup known as Pwakinyo. Throughout the rest of Thailand, there are also Sgaw, Po and the famous "Long Necked" Karen groups. Each of these subgroups has their own dialects which are not mutually intelligible. The vast majority of Karen people today are living in Burma but due to the recent history and continued social upheaval, thousands of Karen have become refugees in neighboring Thailand and internationally in Australia, the United States of America and Canada.

Religiously, Melaoop is approximately 35\% Buddhist and $65 \%$ Christian. Karen are one of the most evangelized and Christianized minority groups in Thailand. Interestingly, Thai Karen were first evangelized by Burmese Christian Karen in 1867 (Hovemyr 1989, 113). Shared cultural ties and a lack of Western missionary involvement during the early evangelization tours undoubtedly were key reasons for the success of mass religious conversion amongst the Karen people.

During my research time in Melaoop, I did a home stay with a Pwakinyo family of four: Tanin (father), Naa (mother), Rit (first born, son) and Siua (second born, daughter). The family functioned as the gatekeeper to the broader village community. My host family lived on a compound with two other households that included extended relatives: Wit (maternal uncle), Pen (his wife) and Bubble (daughter) in one home and Poopoo (grandfather), Piipii (grandmother), Ann (maternal aunt) and occasionally Wasan (uncle) in the other home.

In order to properly understand the field site, I must briefly describe my key informants. Tanin works a salaried job with a local NGO that services children at the hostel. He is the head NGO manager for Melaoop village. He is also a chairman of the village church. In addition to this, he aids in agricultural production when needed. Naa is the main agricultural force in the 
household. The rice paddies are jointly controlled by her and Piipii. In addition to this, she is a housekeeper: taking on the duties of child rearing, cooking, house cleaning, laundry and raising pigs. Furthermore, she is an active member of the church's women's group and children's school volunteer staff.

Wit is a farmer first and foremost. He supplements the family income by working additional wage labor jobs during the down agricultural seasons. Unlike Tanin he is not very involved in the church or the school. He was actively involved in local politics and was formerly the village headman. Regularly he will take upon himself household responsibilities like laundry, cleaning, cooking and home repair. Pen, like her husband, is also primarily a farmer. In addition to this, she works wage labor jobs, mostly at the rural health clinic. She also occupies the role of caregiver and cook for her family and many of the local neighboring children are constantly at her home. She is actively involved in the choir and teaches Sunday school. Wit and Pen regularly supplement their family's diet with gathered foods like ferns, bamboo shoots, snails, fish and wild fruits.

Melaoop, with its unique geographical, biological and socio-cultural factors proved to be a vibrant field site.

\section{METHOD}

Prior to any data collection, my research proposal was approved by Messiah College's Institutional Review Board. Once at my field site, I collected data between February 25, 2012 and July 13, 2012. Throughout the ethnographic study, I relied upon various methods of data collection. The most common and overarching data collection method was participant observation. My intention to do research was made known by explaining many ways and many times the reason for my presence in the community (Babbie 2008, 334-335). Within my host family's household, I was given my own room for sleeping and studies but all other social life was open to me as a guest and, eventually, fictive kin. While living with my host family, I joined the local choir, volunteered at the village church, aided in home construction, taught English language lessons, tended pigs, helped prepare and plant rice paddies and was an active member of wedding rituals: not to give an exhaustive list.

During periods of participant observation, I carried small notebooks around with me and jotted down notes concerning what I observed. This was in order to record the necessary empirical observations and personal interpretations key to adequate data collection (Babbie 2008, 340). Each evening, I would fill in and flesh out my notes from the day. Most of this was done electronically in a password protected document. If not done electronically, I took notes by hand and kept them in a locked duffle bag.

To further inform my research, I employed spontaneous qualitative interviews. Commonly taking the form of conversation, spontaneous qualitative interviews were exclusively conducted in Thai. I recorded these interviews in the same notebooks I carried around with me mentioned above. These interviews, however, were kept within printed media rather than electronic media.

I also used planned interviews as another means of data collection. I conducted four planned interviews. Participants were asked for their consent and only after receiving consent did I interview the interviewees. My interview questions consisted of five broad themes detailing the interviewee's education, religious life and beliefs, role in family life, opinion on governmental development and their view of the environment. I recorded these interviews in print media.

Data were analyzed using either a naturalistic ethnographic approach or an ethnomethodological approach. Observations and interviews were analyzed with a naturalistic ethnographic approach in order to relate accurate descriptions of the objective social realities present within this case study (Babbie 2008, 321). Ethnomethodology was used to analyze, primarily the unplanned interviews to collect implicit social data (Babbie 2008, 322). In order to do this, I read and reread all ethnographic notes to highlight patterns and themes both explicitly stated and implicitly present. With this data, I further subcategorized it as what the Karen of Melaoop consciously said or did and what I as a researcher observed in daily life. My original inspiration for such a method, one in which I aim to dispassionately portray the voice of the Karen while also out rightly recognizing my own subjective observations comes from an ethnographic method used by Richard Katz ${ }^{1}$. In Katz's ethnographic study, he takes particular care to distinguish between his voice and those of the Dobe Ju'hoansi he studied. 


\section{KAREN AND NEGOTIATED DEVELOPMENT: IMPLEMENTED} CULTURAL CAPITAL

Development, I came to learn, is one of the most common discourses of Karen daily life. With the advent of the road and new governmental seat, the hot topic button of development is constantly pressed. How the people of Melaoop have come to articulate, understand and become agents in the dialogue of development is worth exploring because of the insight it can provide to the ongoing discussion of development. What the Karen themselves say and do about development is as important as my own outsider's interpretation.

The means by which Karen negotiate development in Melaoop can be understood in three broad ways: engaging the market and capitalizing on cultural products, protecting or conserving the resource rich environment and accepting and utilizing external development agencies and agendas. Important to note, these strategies for negotiating development are gendered and based in traditional Karen gender roles.

Engaging the Market and Capitalizing on Cultural Products

The first technique of negotiated development is the capitalization and commodofication of cultural products. This is best seen in the garment and textile ventures undertaken by many women in Melaoop. Traditionally, garment production was exclusively the role of women and for the most part has remained that way in light of recent cultural and economic changes. Not once did I see a man weave or even sew fabric. As such, this first form of negotiated development is practiced by Karen women. Gei, the pastor's wife, is one of the foremost weavers of the village. She produces so much that she must take stock of her men's and women's shirts, blankets, traditional headdresses, skirts, scarves and handbags. With the aid of a family friend she has been exporting her wares to Chiang Mai for retail. Nor is her economic venture unique. Pen and Buo Touh, Pen's closest friend, both irregularly produce textiles for sale in order to support their children's educational costs. This production, networking and marketing of goods is one way in which the Karen women transform their social capital into hard economic resources, particularly supplementary family income, especially during the traditional off season in the agricultural cycle.

Capitalizing on cultural products is not limited to what is manufactured in the home. In fact, there is even a market for the traditional Karen guest oriented way of life. On the outskirts of Melaoop proper is a newly constructed eco-lodge and guesthouse owned by a foreign man and Thai national. Supplied with modern conveniences like beer, ice and English leisure books, vacationers can enjoy an escape into nature and traditional tribal life at this guesthouse. Opinions about the guesthouse are decidedly mixed and ambiguous but the fact remains though, that many women are employed, and happily so, in the service of the guests. When I asked what travelers do here, Pen replied that they come to see the nature and the Karen people. The Karen who work at the guesthouse, in short, are commodifying their guest ethic, tribal status and natural resource management as a means of profiting from the opportunities development has brought.

\section{Protecting the Resource Rich Natural Environment}

The simple fact that this eco-lodge can market the Karen protected and tended natural resources is prime example of the intersection between two important development negotiating techniques: the commodification of cultural products and the preservation of nature (which is also a unique cultural product). Resource conservation and forest protection is grounded in the long standing Karen environmental ethic. Traditionally, Karen believed themselves to be residents and caretakers of the forest. According to myth, right relationship with the natural world is vital to the well-being of the Karen people. The importance of nature is seen particularly in their own understanding of humanness; as they have named themselves $P w a$ ' kinyo, literally forest people. The importance of resource management is selfevident. This can best be interpreted in light of cultural materialism. If your basic needs are being met by forest products, naturally there will be powerful cultural taboos and norms to protect the status quo and continued fecundity of the infrastructure.

This negotiation technique, like the previous one, is also gendered. Conservation and resource protection is considered male domain. Hunting, fishing, material collection and ritual observation outside of the home were traditional Karen male roles. (Yoshimatsu 1989, 60) These gender roles have continued as the Karen relationship to their natural world has been renegotiated in light of development. While women certainly had an opinion about the proper relationship with the natural world ${ }^{2}$, men that I talked to were the most vocal about the need for con- 
servation. Tii, my neighbor, talked much with me about his love for the forest and the need to care for it. Wit's aspirations for his children to see the forest and enjoy the land further illuminate this. But the most vocal and opinionated was Wii Jii, another neighbor and fisherman, who talked about the spiritual necessity of caring for the land and the injustice of the wealthy who destroy it.

Additionally, all of these men have a high view of conservation NGOs. Both Wit and Wii Jii have worked with conservation NGOs. Wit, in particular sees NGO work as the best kind of work. Nearly every day he would mention the benefits to people and the land of working with conservation NGOs. This high view of NGOs is interesting especially when I consider the fact that he could not name a single conservation NGO when I asked. He could, however, direct to friends who had personal work experience with NGOs. When I mentioned my own interest in working with conservation or sustainability, both Wit and Wii Jii were openly supportive of my career hopes. They even suggested I come back and work in Melaoop.

Accepting and Utilizing External Development Agencies and Agendas

In addition to conservation NGOs, Melaoop has other $\mathrm{NGO}$ and governmental development initiatives present that cover a range of development issues like education and health. The most prominent development oriented institutions include: Compassion International, the government school and the rural health clinic. Compassion is an American run NGO that works primarily through local churches to educate and support children. In Melaoop, Compassion runs a hostile for children and infant care classes for young mothers. The school is governmentally run as is the rural health clinic. Both are part of the larger Thai government's goal to provide education and healthcare to its citizens. The head of Compassion, Tanin, school principle, Udom, and clinic coordinator, $\mathrm{Na}$, are all ethnically Karen and residents of Melaoop. What is negotiated is how the external development goals are implemented by and in the community. When asked, Tanin said he works with Compassion because it is a way to help support the children. He, as the local Compassion manager, has a say in the implementation of development agenda and strategy. Tanin's comment is a prime example of negotiated development.
AN OUTSIDE THOUGHT ON NEGOTIATING DEVELOPMENT: LATENT CULTURAL CAPITAL

As previously mentioned, the Karen of Melaoop are already engaged in negotiating development. What precedes is what is already being done. However, there are other techniques and institutions that I have observed and consider worth highlighting. What I found was that beyond the three currently implemented strategies of negotiating development, three other institutions appeared to have latent potential in shaping the path of development in Melaoop: communality, gender and religion.

\section{Communality}

Communality is often seen in terms of communal property or production rights. While greater stratification has emerged within Karen society due to changes in agricultural production, exposure to globalization and new economic incentives, there has been a maintained understanding of communality (Hayami 1997, 559). I noticed this communality evidenced in the act of visiting and sharing. Being sociable and visiting people is common practice among Karen. It is seen as leisure and business. Tanin would often "go visiting" to the next village to socialize with his employees at Compassion and also discuss business. Whenever he needed advice or aid he would "go visiting" to respected members of the community like Aj Mountain. The community orientation becomes evident when considering the daily 
occurrence of visiting and the social capital and communication it fosters.

The other indicator of communality amidst Karen that I noticed was the constant sharing or material goods and supplies. Food was shared between Grandma, Naa and Pen. Shoes, hats, and agricultural implements were also shared in kind between these households and even Mugha's household a short walk up the hill. Leisure artifacts like television, guitars and volleyballs were all also commonly used between the households. Even bathrooms, which each household had, could be used in common. Sharing is by far the biggest indicator of communality.

The implementation of communality amidst the Karen of Melaoop is a tool I see that can be used in many ways to negotiate development. Resource pooling and sharing is one way to ensure the wellbeing of the community. Karen communality is just such a practice that will safeguard against the vast wealth gaps that often occur with rapid modernization and capitalist market paradigms currently infiltrating traditional Karen land and culture.

\section{Gender}

Gender is one of the most commonly investigated social institutions and one of the most powerful in affecting social relationships. According to the World Bank, gender equality is a key indicator of lower levels of poverty and higher levels of sustained economic growth (World Bank Group 2013). Consider then the important fact that Karen culture was traditionally and still is matrilocal. With modernization, the previously female focused culture has become more egalitarian but still maintains many matrilocal practices and rituals. In the past, when a young couple was newlywed, the man had to relocate to his wife's household. This is no longer exclusively the norm, however, it is still the most common practice. Tanin, Wii Jii and Jopoh, the local pastor, all relocated from different villages to Melaoop when they married Melaoop women. Another example of Karen matrilocal culture is the fact that rice field inheritance is usually passed down from mother to daughter. Naa and Phiiphii are an example of how the rice fields were maintained in the family by female lineage.

Two other examples are worth highlighting here. The first is that ubiquitously, childcare is a woman's role. This has implications for education, health, identity and both ecological and cul- tural conservation because when women are the primary caregivers, they are also the primary shaping factor upon the next generation. This caregiving relationship is one that I noticed as an area of further exploration in negotiating development.

While the assumption of caregiving roles often leads to a lower status for many women and a subsumed role in family and social discourse, that is not the case amidst the Christian Karen of Melaoop. Women are strong voices and social actors in the household and the community. For example, Phiiphii was vocally fighting against the installment of a Buddha room at the local school. While she could not vote on the issue, her opinion was known and was considered during the village council to decide upon the issue. What I see as a vital resource for future Karen is the extent to which not only male but also female voices are represented in public discourse. Greater sustained development will only occur in contexts in which gender equality is the norm. The Christian Karen of Melaoop have a latent potential to sustain greater gender equality already present in their matrilocal traditional practices.

Religion

The final institution I observed to have social clout is religion. In particular, the Christian Karen church. Melaoop church is part of the Karen Baptist Convention, an autonomous Karen church with loose historical ties to the American Baptist Church. However, those ties were severed late in the 19th century and the current indigenous led church emerged. Whatever the particular origins of the Karen Baptist Church, it is important to consider it now in light of the role it plays in the social construction of reality. The church, as a cultural construct, assumes an objective reality of its own and thus has the ability to impact individuals and other social structures. This process has particular importance in the context of Melaoop.

I see the Karen Baptist Church as a unique institution specially situated as a means of expressing and preserving ethnic identity. The church in Melaoop was the only social group teaching the Karen language to the younger generation. The practical rationale for this is that the Bible and hymnal is written in Karen, thus active church members must be literate in order to participate in worship. Worship itself often was comprised of hymns with nationalistic lyrics blended with escapism eschatology promising a better life after death. Furthermore, traditional 
dress was worn weekly when attending church. These are just a few examples of the nearly inseparable connection between ethnic identity and faith that I observed.

A strong ethnic identity, present within the church, provides the social cohesion necessary for the creation of social capital that can easily be transformed into either human or material capital. Church members with a strong ethnic connection can mobilize their resources efficiently and effectively. The annual Karen Baptist Convention is a prime example of this. One village is tasked with hosting the convention and must provide food, entertainment and shelter for the entire Karen Baptist Church of Thailand. Amazingly, resources are consolidated and everyone's needs are met for the week long convention. Furthermore, the church is a cultural bank of sorts, resisting many incursions of modernity. These observations lead me to believe that the church can be a crucial player in the future negotiation of development, in particular, large scale social action or pan-Karen social movements.

\section{CONCLUSION}

Development is a multifaceted and powerful force in the Melaoop community. It has external and internal components, for example the outsider Thai government policies and the local desire for better infrastructure and assurance of utilities like electricity and water. Furthermore, it is fluid and constantly negotiated by the local community it directly impacts. 
My research indicates that there are already multiple means of negotiating development currently being implemented in Melaoop. These means of negotiating development are implemented social capital that arises from both the particular environmental context of the Karen as well as the unique social reality as highlighted by the insights of cultural materialism and the social construction of reality. The engagement of the market and the commodification of cultural products, the protection of natural resources, and the engagement with development agencies and agendas are the three broad practices I observed during my ethnographic study. What this means is that the local community has cultural resources and social capital which they are utilizing to negotiate the direction of development within their own particular village context. The Karen of Melaoop are not passive actors but vibrant agents in active dialogue with development.

Beyond the already implemented negotiation processes, there is a great latent potential in the Karen institutions of communality, gender and religion. These three institutions, as I have termed them, provide a basis of social capital that could be readily used to foster greater social cohesion and directed change. Communality is a practice that acts as a social cohesive and glue. There can be no positive negotiation of development if the community is fractured. Gender is also vital to positive development because the role of women as care-giver and primary socializing agent of the next generation has far reaching implications for successive generations that subsequently will also negotiate development. What happens with this generation of mothers will have repercussions in the future. Finally, religion, the Karen Baptist Church in this particular context, is also a powerful institution with many physical and social resources at their disposal. The church in Melaoop is one of the best endowed institutions because of social commitment to its well-being. This latent store of both physical and cultural resources can be further implemented to engage the discourse of development.

My focus on these three institutions of communality, gender and religion is just that, my focus. Most discourse in Melaoop centered around the first three implemented processes of negotiating development, rather than the three institutions I consider to have latent potential. This proves to be a dilemma then in many ways. First, because I believe development should be endogenous, I must suspend what I believe to be potential avenues for developing. My outsider position does not prevent me from engaging development discourse but rather establishes my voice as one of secondary or periphery importance to those directly impacted by development. Additionally, the question is raised, do the particular and unique ways in which the Karen of Melaoop already negotiate development have broader applications? These negotiation techniques are effective for this context and are local solutions. I would argue, however, that because these are local solutions they do in fact have broader implications. The very fact that endogenous development is happening in Melaoop proves that the rhetoric of endogenous action is not just lofty ideas and pleasant words, but rather is a tangible development process.

Future exploration of this topic could and should include comparative ethnographic studies. One of the greatest assets but also limiting factors of this study is the particularity of this study. The depth of knowledge learned through qualitative study of one particular community comes at a cost to the breadth of knowledge possible. I suggest then, that further study be conducted in communities representing various ethnic, religious and linguistic groups that are also in the process of negotiating development. A greater breadth of data can only aid in our understanding of the complexities of negotiated development for those most impacted by it.

1. Katz, R., Biesele, M. \& St. Denis, V. 1997. Healing Makes Our Hearts Happy: Spirituality and Cultural Transformation Among the Kalahari Jul'hoansi. Rouchester, Vermont: Inner Traditions.

2. Naa was opinionated about the local fish poaching and artificial rain programs of the Thai government. 


\section{REFERENCES}

Babbie, E. 2008[2005]. The Basics of Social Research, 4th ed. Belmont, California: Thomson.

Berger, P. 1990. The Sacred Canopy. New York: Anchor Books.

Chaiken, M. S., Dixon, J. R., Powers, C., Wetzler, E. 2009“Asking the Right Questions: Community-Based Strategies to Combat Hunger." NAPA Bulletin 32: 42-54.

Coleman, J. S. 1988. "Social Capital in the Creation of Human Capital." In Readings in Social Theory: The Classic Tradition to Post-Modernism, edited by James Farganis, 266-280. New York: McGraw-Hill Companies, 2008.

DeTemple, J. 2008. "(Re)Production Zones: Mixing Religion, Development and Desire in Rural Ecuadorian Households." Journal of Latin American and Caribbean Anthropology 13, no. 1: 115-140. Academic Search Complete, EBSCOhost (accessed September 17, 2012).

Ekins, P. 1992. A New World Order: Grassroots Movements for Global Change. London: Routledge.

Güven, A. B. 2012. "The IMF, the World Bank, and the Global Economic Crisis: Exploring Paradigm Continuity." Development and Change 43, no. 4: 869-898. Academic Search Complete, EBSCOhost (accessed December 1, 2012).

Harris, M. 1979. Cultural Materialism: The Struggle for a Science of Culture. New York: Random House.

Hayami, Y. 1997. "Internal and External Discourse of Communality, Tradition and Environment: Minority Claims on Forest in the Northern Hills of Thaliand." Tonan Ajia Kenkyu (Southeast Asian Studies) 35, no. 3: 558-579.

Hovemyr, A. P. 1989. "In Search of the Karen King: A Study in Karen Identity with Special Reference to 19th Century Karen Evangelism in Northern Thailand." PhD diss., University of Uppsala.

Hunn, E. S. 1999. "Value of Subsistance for the Future of the World." In Ethnoecology: Situated Knowledge/Located Lives, edited by Virginia D. Nazarea, 23-36. Tucson: University of Arizona Press.

This work is licensed under a Creative Commons AttributionNonCommercialNoDerivs 3.0 Unported License.
Kabuye, C.S. 1999 “Am I My Brother's Keeper?"In Ethnoecology: Situated Knowledge/Located Lives, edited by Virginia D. Nazarea, 263-271. Tucson: University of Arizona Press.

Katz, R., Biesele, M. \& St. Denis, V. 1997. Healing Makes Our Hearts Happy: Spirituality and Cultural Transformation Among the Kalahari Ju|'hoansi. Rouchester, Vermont: Inner Traditions. 
Knauft, B. M. 2009. “Ritual form and Permutation in New Guinea: Implications for Symbolic Process for Socio-political Evolution." American Ethnologist 12, no. 2: 321-340. Academic Search Complete, EBSCOhost (accessed September 13, 2012).

Paladino, S. 2011. "Tracking the Fault Lines of Pro-Poor Carbon Forestry." Culture, Agriculture, Food and Environment 33 no. 2: 117-132.

Povinelli, E.A. 1995. “Do Rocks Listen? The Cultural Politics of Apprehending Australian Aboriginal Labor." American Anthropologist 97 no. 3: 505-518.

Sachs, J. 2011. "A Pioneering Perspective." Harvard International Review 33, no. 1: 78-82. Academic Search Complete, EBSCOhost (accessed November 23, 2012).

Samaddar, A. 2008. "Traditional and Posttraditional: A Study of Agricultural Rituals in to Technological Complexity among Rice Producers in Two Zones of West Bengal, India." Culture and Agriculture 28, no. 2: 108-121. Academic Search Complete, EBSCOhost (accessed September 14, 2012).

Sivaramakrishnan, K. 2008. "Crafting the Public Sphere in the Forests of West Bengal: Democracy, Development, and Political Action." American Ethnologist 27, no. 2: 431-461. Academic Search Complete, EBSCOhost (accessed September 14, 2012).

Torri, M. C. and Herrmann, T. M. 2011. "Spiritual Beliefs and Ecological Traditions in Indigenous Communities in India: Enhancing Community-Based Biodiversity Conservation." Nature and Culture 6 no. 2: 168-191.

United Nations Development Programme. 2013. “Millennium Development Goals: Eight Goals for 2015." Last modified 2012. http://www.undp.org/content/undp/en/home/mdgoverview. html

World Bank. 2013. "Why is Women's Economic Empowerment Important for Development?" http:// siteresources.worldbank.org/INTGENDER/Resources/womens_economic_empowerment. pdf

Yoshimatsu, K. 1989. "The Karen World: The Cosmological and Ritual Belief System of the Sgaw Karen in Northwestern Chiang Mai Province." Final Research Report. Bangkok, National research Council of Thailand. 